\title{
Open forums for teaching in an open online world
}

David R. Geelan

School of Education and Professional Studies, Griffith University

Parklands Drive, Southport QLD 4215, Australia

Email: d.geelan@griffith.edu.au

This is an author's preprint copy of a paper published in the International Journal of Continuing Engineering Education and Life-Long Learning, Vol. 25, No. 1, 2015: pp. 28-38.

\begin{abstract}
Discussion forums used for teaching and other purposes in university courses are most often 'closed', in the sense that they are located within course management systems (CMSs) and password protected. This also means that they typically only last one semester and are associated with a particular course. This approach has advantages, but also costs, and this paper considers the alternative of using 'open' forums - forums available to the open internet - for teaching purposes across courses and programmes. An open forum was created and used in courses across one year of science education, drawing in students in the courses, students in similar courses at other universities, alumni, teachers and science educators. The forum will continue to be available to all participants after they complete any particular course, or their programmes at the university, and will develop as a 'living' educational community across multiple courses, levels and programmes. The costs and benefits of 'open' versus 'closed' forums are discussed, and contexts in which each may be more effective considered.
\end{abstract}

\section{Introduction}

Web-based discussion forums have been a feature of online teaching since its beginnings in the mid1990s (Kim, 2013; Tallent-Runnels et al., 2006). They offer a number of affordances that are not offered by either traditional paper-and-mail modes of distance education or face-to-face teaching and tutoring: though of course, like any medium, they also come with costs. Discussion boards are 'online' in that they are web-based, and 'asynchronous' in that participants post at different times and do not have to be 'present' (participating) at the same time (in contrast to teleconference, videoconference and chat, which are 'synchronous' media). They have been used purely incidentally for discussion of 'housekeeping' in courses, more centrally for discussion of the key ideas, and also as assessment tasks (Geelan and Taylor, 2001; Hew et al., 2010). In some instances discussion forums have also been seen as adding social enrichment to courses in which all the actual learning activities occur using other media. The focus of the discussion presented in this paper, however, is on contexts in which the discussion forum is seen as an integral part of the course(s), with an emphasis on deepening and broadening students' engagement with and understanding of the conceptual content of the course(s). Discussion forums are typically text-based with options for including images, audio (Dringus et al., 2010) and video also available. The focus in the present paper is on textual posts and discussions.

While a variety of models have been employed, the most typical approach in university and college courses has been the use of discussion forum functionality within course management systems (CMSs) such as Blackboard and WebCT. Such forums are typically 'closed', in the sense that they are accessible only to the people participating in the course - instructors, tutors and students - as well as anyone the instructor chooses to invite to participate (such as a guest speaker or external expert). 
They are typically associated with a single, one-semester course, and become unavailable to the students - effectively 'dead' - when the course finishes.

Such 'closed' discussion forums have significant benefits, but also come with costs. This paper considers these costs and benefits, and contrasts them with the costs and benefits of the use in teaching of 'open' discussion forums that are accessible to everyone who wants to participate.

Neither approach is a panacea, of course. This discussion is intended to advocate adding open forums to the teaching repertoire, and perhaps using them to a greater extent for the benefits they offer, but closed forums also continue to have value.

\section{A discussion forum autobiography}

My own history of web-based discussion is relevant to the issues discussed in this paper, because (arguably) it is through experience that online teachers learn to navigate the ethics and mores of online discussion. As a side note, although there has been little or no research into the question, I suspect that one of the unacknowledged issues with moving to more online teaching is that courses are advocated and designed by people who have similar histories to myself - hundreds or thousands of hours online in a variety of communities and media - but are sometimes then taught by people with much less experience of the online world. There would be value in exploring some of the 'preconditions for successful online teaching', and discovering whether the evidence supports the plausible suspicion that those with more and broader experience are, other things being equal, more effective.

I spent 1993 and 1994 teaching at a small teachers' college in Papua New Guinea, and moved to Perth in 1995 to begin my doctoral studies at Curtin University. The World Wide Web was in its infancy (the internet is much older), and I discovered it for myself at Curtin. I immediately took to the online world, joining Usenet newsgroups and e-mail discussion lists around the philosophy of science and cyberpunk/hacker culture, two of my obsessions of the time.

I also saw the potential of asynchronous web-based discussion forums for distance teaching, and developed and taught my first online course in 1995. It was immediately clear that the discussion forum was the 'value add' of online courses, particularly at that (pre Web 2.0) time when the readings were still all text and the assignments all still submitted in text form.

My paper with my mentor and colleague Peter Taylor (Geelan and Taylor, 2001) details the processes we went through in several successive iterations of an online course, in attempting to 'embody our values in our teaching practices'. It includes an account of one student who was very resistant to our approach and the new demands, and who suggested that we had behaved unethically. While we resisted her claims at the time, in hindsight we certainly should have been more explicit and up front with our students about our intentions... but at the time, our intentions were still in the process of becoming explicit for us! Dawson et al. (1999) further outlines some of the commitments and challenges encountered as we sought to fit the medium to the message (McLuhan and Fiore, 1967) and vice versa.

Discussion forums continued - and continue - to be an important part of my life. The alt.cyberpunk Usenet group led me to the books of William Gibson (or was it the other way around?), and when he created a website in 2003 । was an early member of the discussion forum (http://williamgibsonboard.com/eve/forums/a/frm/f/2866012481). The forum has developed into a lively international community that has led to a number of weddings and couples as well as regular international meetups. On one memorable occasion I had dinner in Vancouver with fellow fans from 
Mexico, France, the USA and Canada - and William Gibson. I have been a member of the forum for more than ten years, and count many of the denizens as personal friends, and my discussions there have been influential on my ongoing intellectual development. I have posted more than 16,000 posts on the forum, and others have posted more (I post there, and many places on the web, as 'Bravus'). The 'Random Thoughts' subforum, the most active one, has over half a million posts in total. The discussions started out being about William Gibson and his books and cyberpunk science fiction more broadly, but have expanded to being about anything and everything.

I have also had a blog (http://www.bravus.com/blog/) for more than eight years, and posted over 1,800 posts there. Facebook discussion groups are less satisfying - because much more ephemeral than discussion forums, but seem to be where a lot of the 'action' is in informal online discussion at the moment - and, increasingly, in Facebook pages associated with courses.

Teaching many courses in web-based and flexible/mixed modes means that I have used, facilitated, participated in and moderated web-based discussion forums in most of the 18 years since that first online course. This basis of experience - both private/personal and professional - informs my perspectives and actions in relation to how open and closed discussion forums might be valuable for teaching and learning. It also offers at least some tentative ideas about the ethical and moral implications of the use of discussion forums in general, and open forums in particular, in education.

\section{Open forums - costs and benefits}

An extensive review of literature in the field of web-based teaching in higher education did not reveal even a single paper describing open forums of the kind described here. While many massively open online courses (MOOCs) use discussion forums as part of their approach to delivering learning experiences to very large groups of students (Kellogg, 2013; Mak et al., 2010), the uses and purposes of such forums are different from those in smaller classes where instructors play a more explicit and direct role in connecting with students. The following discussion of the costs and benefits of open forums, therefore, are drawn from my own experience and from thinking through these issues in the process of developing and facilitating the open forum described later in this paper.

The costs of an open forum are

1 reduced privacy and security for participants

2 the financial costs of operating a forum

3 the threats from spammers and 'trolls' who post only to cause anger or distress.

It is a commitment for a teacher to develop and maintain a forum in the long term, since the second and third of these costs fall largely on the instructor (or on his/her technical support team). The commitment is open-ended, if the open forum is intended to exist and grow for long periods.

Some students - for a variety of reasons - would prefer that what they write not be available to anyone at all who cares to read it: they would rather post, if at all, in a closed forum. This view can to some extent be addressed through discussing 'security through obscurity' and encouraging them to post things they would be comfortable sharing with the world (for example, avoiding criticisms of colleagues and other individuals), however some of these concerns are also quite legitimate. In the examples described in detail later in this paper, I have chosen to use an open course in one application and a closed course in another, and this issue - of privacy and security for participants is one of the reasons for the decisions to use different kinds of forums for different purposes. 
I have subscribed to a web space service provider since the late 1990s. It hosts my home page and blog, as well as images and audio I want to share, the open forum described below and other forums I use for other purposes. I pay a little over $\$ 100$ per year for the service, and the site includes the forum software free. Registering the domain name 'bravus.com' which I use for all my online activities costs around $\$ 15$ per year, but this is not necessary in order to operate a forum. I have also had to learn to use and administer the website, however other academics who wish to operate open forums but have not developed these skills are likely to be able to employ someone to set up the forum, and learn to administer it themselves.

Spammers will try to advertise anything from designer sunglasses to erectile dysfunction medications, and will use software 'robots' to register users on the site to do so. This is a persistent annoyance that requires constant vigilance, and there's not really a simple way to address it. It is probably the single 'cost' that most often makes me think about whether I might not be better off with a nice, safe, closed forum.

The key benefits of an open forum, in my view, are

1 its openness to the world

2 its persistence through time.

An open forum allows learning and discussion to occur in a way that is engaged with others - at other universities, in schools and (for my purposes in science education) in science, locally, nationally and internationally - and with the worlds of science and school education within which science teaching is located. By being able to invite participants from other places and at other stages of the process of becoming a teacher, students' conception of their own profession is expanded and contextualised in ways that are less possible in a closed forum, even with invited guest posters.

In a situation in which posting is based on interest rather than required assessment, the persistence of posts in an open forum, to which posters retain access over months and years, makes posting more compelling and desirable. It is possible to revisit past posts, draw on them, discuss them later, and for threads to run for many years. Some of the threads on the William Gibson Board are more than ten years old and still going strong.

\section{Closed forums - costs and benefits}

Andresen (2009) addresses some of the costs - both financial and in terms of instructor time - and benefits of discussion forums. The examples he uses and the literature he reviews are from what would be called 'closed' forums in terms of the distinction made in the present discussion.

In many ways, the costs and benefits of a closed forum are the direct opposite of those for an open forum. In terms of costs, it is the lack of openness to the world and persistence through time that has convinced me that closed forums are not always the appropriate tools for my educational purposes. In terms of benefits, these tend to boil down to the negation of the costs of open forums: more privacy for students, (usually) no direct financial costs to the teacher using the forum (because the university provides the infrastructure), and much less intrusion from spammers and trolls. It is possible that in a large course there will be 'home-grown' trolls among the student group, but the sanctions available are likely to keep this to a minimum.

Technical support staff of the university also typically support closed forums, so it is not necessary for the instructor to learn to operate forum software or administer details like adding users. 
Having briefly discussed some of the pros and cons of each kind of discussion forum, the following section of this paper exemplifies some of these issues with examples from my own teaching practice.

\section{An open and a closed forum in practice}

My current teaching practice at the Gold Coast campus of Griffith University is in science education, for teachers teaching at all levels of schooling. During Semester One, I teach a course in Middle Years (Year 6-10) science education: what is called a 'curriculum and instruction' course in North America, focusing on the 'pedagogical content knowledge' (Shulman, 1986) of science teaching. In Semester Two, I teach some of the same students - who are participating in a one-year Graduate Diploma in Education programme - in a Senior (Year 11-12) science education course. I also teach a large course (approximately 300 students) in Primary (Year 1-7) science education, across three campuses (Gold Coast, Logan and Mt Gravatt), lecturing by videoconference and using local tutors.

Buchanan (2011) and Convery and Cox (2012) offer good overviews of the ethical issues raised by research in web-based contexts such as discussion forums. In terms of the research ethics of the material reported in this paper, I have not gained research ethics clearance to collect data from the students in any of these courses, or the other people who post in the open forum, and have not gathered such data. I am writing only about my own intentions and experiences in relation to the forums - the 'data' are my own experiences, and this paper takes a 'scholarship of teaching and learning' research approach.

For the students in the Middle Years and Senior Secondary courses, both this year and in coming years, I developed an 'open forum' (http://www.bravus.com/tribes/), hosted privately on server space that I pay for, and administered and moderated by me. If the forum grows as I hope it will, it will continue to be available for many years, and will be available to former students once they graduate and become teachers. Unlike posts in closed course websites (and on Facebook pages), their posts will remain available to them and others, to be referred to and re-discussed. Further, former students who become teachers and continue to participate will form an amazing resource for future students in the courses I teach.

During Semester One, 2013, a number of students (perhaps 30\% of the whole class) posted in the forum, and more registered and read, but a number of other people were also invited and participated. These included students in teacher education programmes at other universities, practicing science teachers working in schools and science educators at other universities. I would also like to invite working scientists to participate in future. The plan is to develop a 'community of practice' (Balaji and Chakrabarti, 2010) that persists over time and reaches out internationally much as the William Gibson Board has.

This is the dream: what of the experience to date? The forum has been open and operational for one semester, and has been a qualified success. There have been 290 posts on 77 topics to date. The member number on the site is 290 , however many of these accounts are set up automatically by spambots. I currently spend a few moments each day deleting new accounts set up this way, and this is one of the realities of running an open forum: an administrator will have to spend time fending off attacks from spammers.

A number of students posted and participated, both on topics from the course (including challenging or questioning ideas I had discussed in lectures, which was fantastic!) and on science education and teaching more broadly. The site was opened to students in another course I taught that was not focused on science education, but participants were all drawn from the science education group. 
The forum does not yet have a 'critical mass' of posters that is sufficient to give it momentum: when the students left the university to complete their practice teaching, and consequently were very busy, the forum went very quiet. Some students also set up a Facebook page for the programme, independently of the university, and brief queries tend to be discussed there. This is probably a good complement to the forum, and is 'owned' by the students. Another good complementary teaching practice was that I went for beers with a number of the students - all were invited, but those who came along tended to also be those who participated in the forum discussions - on Friday afternoons during the time they were practice teaching.

The open forum is not a required part of coursework. It is not, in any real sense, 'owned' by the university. It is intended to complement my teaching, but in the end it is the property of the community of practice made up of everyone who participates, and my role as administrator is to protect and develop the community. I will continue to advocate the use of the site for the students in my courses, and to make it available to interested people more broadly, and hope that the 'critical mass' of participants will develop over time.

Not all students have participated, or are likely to participate. This is particularly the case in an environment in which students - many of whom have families - are already stretched to the limit by mandated assessment tasks across four courses that 'count'. Without the sanction of 'marks', a forum is a medium that works for some students and not for others. And that is OK: the forum is a complement to studies in science teacher education, and is intended to be useful for those for whom it is useful.

Incidentally, all readers of this paper are cordially invited to read, post and participate in the open forum: http://www.bravus.com/tribes/.

The Primary science education course is part of a four-year Bachelor of Education programme and occurs in the second semester of second year. It is the students' first exposure to science education in their programme, and focuses on the physical sciences. Students go on to a second science education course in the following semester (first semester of third year) that extends their pedagogical content knowledge and focuses on biology and earth and space science.

In the Primary course, I use a 'closed' discussion forum as part of the course website, which operates on Blackboard. That discussion is facilitated by myself and the course tutors, and the site combines students from across the three campuses. It is part of the attempt to create a single large 'virtual class', rather than separate classes on the three campuses. The students are encouraged to do more, but are required to make at least five posts on the course discussion site - three original posts and responses to the posts of two other students. These posts form part of the assessment in the course, and will be marked by the course tutors. The Geelan and Taylor (2001) paper outlines some of the issues in relation to assessment of online discussion forum posts, especially when the content is being assessed for a large proportion of the course grade, rather than receiving just a small participation mark.

The three required original posts are in response to the following three questions:

- Topic One The National Curriculum in Science has three strands - Science Inquiry Skills (SIS), Science as a Human Endeavour (SHE) and Science Understanding (SU). Choose a particular year/grade in the primary years. Outline (but don't list) the objectives under each strand. Describe, using concepts from the course, how the three strands are combined in planning to teach science. 
- Topic Two This is not a formal lesson plan, but an opportunity to outline both how you would teach a particular physical sciences (physics) topic in the primary classroom (to a particular class) and, more importantly, why you have chosen to teach it in that way. It is an opportunity for you to demonstrate what you have learned in this course, and you should describe your reasons in terms of the 'public theories' discussed in the course. You should indicate how you will attend to the Science Inquiry Skills (SIS), Science as a Human Endeavour (SHE) and Science Understanding (SU) strands of the syllabus.

- Topic Three As for Topic Two but with a chemistry topic.

The instructions for the two response posts are as follows:

- Once other students have written their responses to the topics, you should write a thoughtful, reflective response/commentary of about 200-400 words on each of two other students' responses.

The criteria used for judging the quality of posts are made explicit for the students, and are as follows:

1. Demonstrated understanding of science content knowledge, including the nature of science.

2. Demonstrated understanding of course concepts in relation to teaching models and approaches. Evidence of creativity and designing activities to engage a diverse student population

3. Evidence of professional, courteous and critical communication: how you draw on and professionally respond to the ideas presented by others (for the two response posts)

4. Clarity and correct English grammar, spelling and expression: these are formal academic texts in an online environment. You are welcome to use the first person (' $I$ ') in your posts, but should avoid casual, colloquial language.

The fact that the forum postings are part of the course assessment has contributed to the decision to use a closed rather than an open forum for this purpose. There are a number of factors:

1. Given that this is a required assessment task in the course, all students are compelled to participate in the forum discussion. Some students may have privacy or other concerns with posting their work, under their own names, in a forum that is open to anyone in the world who wants to read it. (In an open forum, pseudonyms can be used, but that is likely to be unwieldy when trying to mark assignments for a class of several hundred students.) In the closed course forum, which is password protected, only their fellow students and their teachers can see their work.

2. Students may also have concerns about their intellectual property being stolen and used by others if their work is posted in an open forum.

3. While it is difficult to be absolutely certain that the work submitted by a student in an assessment task of this kind is the student's own work, a closed forum is helpful in ensuring that students do not gain unethical assistance from other students or people outside the course when composing their posts.

4. Open forums are subject to spam and other kinds of attacks - a closed forum can be more reliable for use in a higher-stakes environment where students are required to submit assessment pieces.

Anecdotal evidence tends to suggest that about $10 \%$ of people who participate in forums for their own purposes actively post, while about $90 \%$ tend to 'lurk', reading posts but seldom or ever posting. In an assessment task of this kind where $100 \%$ of students are required to post and interact, 
there may well be resistance on the part of some students. Students in the course include both (a) those who have entered university straight out of high school and are in their late teens or early 20s and (b) a significant number of students who have returned to university in midlife.

While both groups tend to be stereotyped in terms of their attitudes and experience with information technologies, in fact the variation within groups tends to be larger than that between groups. Some students tend to be timid about online posting while others are very comfortable with it. This also applies to examinations, essays and other traditional assessment tasks too, of course: something that is often forgotten when contemplating innovative assessment tasks.

Students in the Primary science education course are invited and welcome - but not required - to participate in the open forum as well as completing their required tasks in the closed forum, particularly as a way of getting feedback from students in the other courses and some of the other people who post and read on the open forum.

\section{Ethical and moral issues in using discussion forums}

Some of the ethical and moral issues that arise from the use of discussion forums in teaching pertain to both open and closed forums, while others are more specific to open forums. In an older paper, Johnson-Eilola and Selber (1996) talk about the boundaries of appropriate discussion in online forums'. They talk about the ways in which communities to some extent 'police [themselves]', but also about the role of moderators and moderation.

In a closed forum that corresponds to a particular course, the moderators (who are usually the course tutors and instructors) have considerable power to enforce appropriate behaviour, by deleting posts and sanctioning students. The names and identities of participants are known and universities have rules in place for appropriate use of online resources.

In the closed forum context, the ethical issues that arise are more likely to be in relation to whether forum discussion is considered to be an appropriate learning experience and/or assessment task. Students are often reluctant to post, fearing that their responses will be judged, or that other students will 'steal' their ideas. To some extent forum discussions involve the development of a more collaborative, rather than competitive, assessment ethic and ethos, and this may require some explicit scaffolding on the part of instructors. Even with such scaffolding, some students may continue to resist. The ethical judgement to be made is one informed by professional knowledge do the affordances of this learning/assessment activity justify its use? The same judgement must also be made, however, about any learning activity or assessment task, and the relative novelty of discussions compared with other forms of assessment such as examinations or essays should not bias instructors against their use.

The issues with ensuring that the work submitted is the student's own are similar to those that arise with any other assessment piece. Using a formal declaration to this effect is part of a solution, and it is possible that in future technologies like TurnltIn will be adapted to the forum context to reduce the possibility of plagiarism. Using original, locally relevant assessment topics and questions can also help to avoid students using text from other parts of the web. Marking should also involve checking for consistency of language and sentence structure.

In the open forum context, with less control, there are other ethical issues. Spammers and spambots are usually more of an issue for the administrators of a site than for the users, although it is possible for inappropriate (e.g., graphic, offensive or pornographic) material to be posted and seen by participants before administrators have time to delete it. 
'Trolls' are people who post in discussions purely with the intention of causing fights and distress. Fortunately so far 'security through obscurity' has served the open forum well, and there have been no active trolls, but at some point some are sure to arrive. Good moderation involves discernment making ongoing judgements about the intentions and effects of posts, and deciding when to delete posts and/or ban posters. The safety of the discussion board community is paramount, but within that freedom of discussion is also very important: it remains a balancing act, in which my personal preference is to err on the side of freedom.

\section{Conclusions}

The issue of the experience base with online discussion that is required on the part of instructors and tutors who are tasked with facilitating such discussion is one that, in my view, requires urgent further research and an ongoing professional conversation. Morris et al. (2005) discuss issues of online teaching and note that as instructors became more experienced in teaching in this mode their confidence and effectiveness increased, but there seems to be no systematic evidence regarding the 'out of school' use of online discussion and its implications for practice.

My own experiences, over almost two decades, have helped me develop skills, values and modes of communication that I believe are essential to effective teaching using asynchronous discussion. It is questionable whether it would be possible to teach these to others, or whether the only way to develop the skills is to dive in... and whether perhaps using forums for personal 'play' is an essential ingredient that offers different insights compared to long experience acquired only in professional teaching contexts.

As I noted in the introduction, it is by no means my intention to suggest that open forums are the way for asynchronous online discussions in teaching. I continue to use both open and closed forums in my own teaching, for their different purposes, and to value both.

I think open forums do raise some ethical and moral issues, as well as practical issues, that require further thinking and research. I am thinking and writing and studying my own teaching practices to contribute to that process, and encouraging others to join the project. New tools - or even old ones repurposed and supported with more informed, intentional pedagogies - are always welcome as we aim to better serve our students' learning.

\section{References}

Andresen, M.A. (2009) 'Asynchronous discussion forums: success factors, outcomes, assessments, and limitations', Educational Technology \& Society, Vol. 12, No. 1, pp.249-257.

Balaji, M.S. and Chakrabarti, D. (2010) 'Student interactions in online discussion forum: empirical research from 'media richness theory' perspective', Journal of Interactive Online Learning, Vol. 9, No. 1, pp.1-22 [online] http://www.ncolr.org/jiol/issues/pdf/9.1.1.pdf (accessed 19 March 2014).

Buchanan, E.A. (2011) 'Internet research ethics: past, present and future', in Consalvo, M. and Ess, C. (Eds.): The Handbook of Internet Studies, Wiley Blackwell, New York.

Convery, I. and Cox, D. (2012) 'A review of research ethics in internet-based research', Practitioner Research in Higher Education, Vol. 6, No. 1 [online] http://194.81.189.19/ ojs/index.php/prhe/article/viewFile/100/192 (accessed 19 March 2014).

Dawson, V., Taylor, P., Geelan, D., Fox, R., Herrmann, A. and Parker, L. (1999) 'The development of epistemological pluralism through a web-based postgraduate curriculum course', in Martin, K., Stanley, N. and Davison, N. (Eds.): Teaching in the Disciplines/Learning in Context, pp.99102, Proceedings of the 8th Annual Teaching Learning Forum, The University of Western 
Australia, February 1999, UWA, Perth [online] http://otl.curtin.edu.au/events/ conferences/tlf/tlf1999/dawson.html (accessed 19 March 2014).

Dringus, L.P., Snyder, M.M. and Terrell, S.R. (2010) 'Facilitating discourse and enhancing teaching presence: using mini audio presentations in online forums', Internet and Higher Education, Vol. 13, pp.75-77.

Geelan, D.R. and Taylor, P.C. (2001) 'Embodying our values in our teaching practices: building open and critical discourse through computer mediated communication', Journal of Interactive Learning Research, Vol. 12, No. 4, pp.375-401.

Hew, K.F., Cheung, W.S. and Ng, C.S.L. (2010) 'Student contribution in asynchronous online discussion: a review of the research and empirical exploration', Instructional Science, Vol. 38 , No. 6, pp.571-606.

Johnson-Eilola, J. and Selber, S.A. (1996) 'Policing ourselves: defining the boundaries of appropriate discussion in online forums', Computers and Composition, Vol. 13, No. 3, pp.269-291.

Kellogg, S. (2013) 'Online learning: how to make a MOOC', Nature, Vol. 499, pp.369-371, doi:10.1038/nj7458-369a.

Kim, J. (2013) 'Influence of group size on students' participation in online discussion forums', Computers and Education, Vol. 62, pp.123-129.

Mak, S., Williams, R. and Mackness, J. (2010) 'Blogs and forums as communication and learning tools in a MOOC', Proceedings of the 7th International Conference on Networked Learning 2010, University of Lancaster, Lancaster, pp.275-285.

McLuhan, M. and Fiore, Q. (1967) The Medium is the Message, Allen Lane, London.

Morris, L.V., Xu, H. and Finnegan, C.L. (2005) 'Roles of faculty in teaching asynchronous undergraduate courses', Journal of Asynchronous Learning Networks, Vol. 9, No. 1, pp.6582.

Shulman, L.S. (1986) 'Those who understand: knowledge growth in teaching', Educational Researcher, Vol. 15, No. 2, pp.4-14.

Tallent-Runnels, M.K., Thomas, J.A., Yan, W.L., Cooper, S., Ahern, T.C., Shaw, S.M. and Liu, X. (2006) 'Teaching online courses: a review of the research', Review of Educational Research, Vol. 76, No. 1, pp.93-135. 